\title{
THE ROLE OF ANAEROBIC METABOLISM IN THE PERFORMANCE OF MILD MUSCULAR WORK. II. THE EFFECT OF ASYMPTOMATIC HEART DISEASE ${ }^{1}$
}

\author{
By WILLIAM E. HUCKABEE² \\ (From the Robert Dawson Evans Memorial, Massachusetts Memorial Hospitals, and the Department of \\ Medicine, Boston University School of Medicine, Boston, Mass.)
}

(Submitted for publication February 4, 1958; accepted July 17, 1958)

Previous studies of the anaerobic metabolism called forth by oxygen lack appeared to suggest that clinically apparent congestive heart failure is always associated with an inordinate degree of tissue anaerobic metabolism and therefore an inadequate delivery of oxygen to body tissues during mild muscular activity (1). Moreover, the data implied that this restriction, in the case of heart failure, was due to inadequacy of cardiac output response and not to failure of other portions of the general oxygen transport mechanism. The percentage adequacy both of overall oxygen delivery and of cardiac output response was low in every case, whether or not oxygen consumption and cardiac output themselves appeared to be abnormal when compared with grouped normal values. In other words when oxygen delivery and cardiac output at any one moment were viewed in relation to the needs of the subject's tissues at the same moment, a much sharper delineation of "adequacy" could be made than if they were compared to the responses of other subjects at other times. This approach to the adequacy of oxygen delivery and cardiac output responses has likewise been directed at the stages of "incipient" congestive heart failure. The present communication presents the results obtained in asymptomatic human subjects who exhibited clinical evidence of heart disease (Class I) and thus had clinical manifestations which are thought to represent earlier stages of a progression which leads ultimately to heart failure.

\footnotetext{
1 Aided in part by a grant from the National Heart Institute, National Institutes of Health, United States Public Health Service.

2 Work done in part during tenure of Research Fellowship and Fellowship as Established Investigator of the American Heart Association.
}

\section{METHODS}

Measurements of rate of oxygen consumption $\left(\dot{\mathrm{V}}_{\mathrm{O}_{2}}\right)$, cardiac output ( $\dot{Q}$ a), arterial blood lactate and pyruvate concentrations per liter of blood water and total body water content $\left(W_{b}\right)$ were carried out in the manner previously employed (1). The mild exercise (supine straight leg raising) was the same as that used for the study of normal subjects and of patients with congestive heart failure and approximated in severity the common daily activity of patients. It has been shown previously that the amount of exercise undertaken (in the "normal" range) has no effect on estimates of circulatory adequacy of the sort reported here (1). The 30 patients were asymptomatic and had never had dyspnea at any time. The diagnosis of heart disease was incidental to unrelated complaints at the time of the first examination. The lesions were chiefly valvular. In Group A, seven of the patients had mitral stenosis, two had predominantly mitral regurgitation, two had both stenosis and regurgitation without clear-cut predominance, two had tricuspid regurgitation, and two had "arteriosclerotic" (senile) heart disease. In Group B, six of the patients had aortic valvular deformity (two had stenosis and four had regurgitation or both stenosis and regurgitation), seven had moderately severe or severe essential hypertension, and two had pulmonic valvular stenosis. No edema or hepatomegaly was found on physical examination, and venous pressures, arm to tongue circulation times and vital capacities were normal. End diastolic pressures in the right ventricle were normal. All the patients considered themselves to be completely well and were either employed at full time jobs or were in school and active in sports. Thus the more numerous group who chose to restrict activity (as a result of medical advice or otherwise) are not represented because of the possibility of error in classification.

The derived quantities used in the section on results were calculated as follows from the observed data (1):

1) Excess lactate $(X L)$ concentration:

$$
X L=\left(L_{n}-L_{0}\right)-\left(P_{n}-P_{0}\right)\left(L_{0} / P_{0}\right) .
$$

$L_{n}$ and $L_{0}$ are experimental (exercise) and control values of blood lactate, respectively; $P_{n}$ and $P_{0}$ are the same for blood pyruvate.

2) Anaerobic metabolic rate (AMR):

$$
A M R=d X L / d t \times 11.2 W_{b}
$$

given in ml. per minute of oxygen equivalents. 
3) Percentage response of oxygen consumption (\% resp. $\left.\dot{\mathrm{V}}_{\mathrm{O}_{2}}\right)$ :

$$
\% \text { resp. } \dot{\mathrm{V}}_{\mathrm{O}_{2}}=\frac{\Delta \dot{\mathrm{V}}_{\mathrm{O}_{2}} \times 100}{\Delta \dot{\mathrm{V}}_{\mathrm{O}_{2}}+\mathrm{AMR}}
$$

$\Delta \dot{\mathrm{V}}_{\mathrm{O}_{2}}$ is the change in $\dot{\mathrm{V}}_{\mathrm{O}_{2}}$ between the near-basal state and a steady state of exercise.

4) Percentage response of cardiac output ( $\%$ resp. $\dot{Q} a$ ) and of arterial mixed venous blood oxygen difference [\% resp. $\left.(\mathrm{a}-\overline{\mathrm{v}})_{\mathrm{O}_{2}}\right]$ :

$$
\begin{aligned}
& \% \text { resp. } \dot{\mathrm{Q}} \mathrm{a}=\frac{\Delta \dot{\mathrm{Q}}_{\mathrm{a}} \times 100}{\Delta \dot{\mathrm{Q}}_{\mathrm{a}}+\frac{\mathrm{AMR}}{\left(\mathrm{Ca}_{\mathrm{O}_{2}}-\mathrm{C}_{\mathrm{V}_{2}}\right)_{\text {exercieo (ex.) }}}} \\
& \% \text { resp. }(\mathrm{a}-\bar{v})_{\mathrm{O}_{2}}=\frac{\Delta\left(\mathrm{Ca}_{2}-\mathrm{C}_{\mathrm{O}_{2}}\right) \times 100}{\Delta\left(\mathrm{Ca}_{\mathrm{O}_{2}}-\mathrm{C}_{\mathrm{O}_{2}}\right)+\frac{A M R}{\dot{Q}_{\mathrm{a}_{\text {ex. }}}}} \text {. }
\end{aligned}
$$

$\Delta \dot{Q}_{\mathrm{a}}$ and $\Delta\left(\mathrm{Ca}_{2}-\mathrm{C}_{\mathrm{v}_{2}}\right)$ represent changes of cardiac output and arteriovenous oxygen difference between the basal state and the exercise; $\left(\mathrm{Ca}_{2}-\mathrm{C}_{\mathrm{V}_{2}}\right)_{\text {ex. }}$ and $\dot{Q}_{\mathrm{a}_{\text {ex }}}$. represent the absolute arteriovenous oxygen difference and cardiac output in the steady state of exercise.

\section{RESULTS}

During the performance of mild exercise the 30 patients with heart disease increased oxygen consumption, cardiac output and arterial-mixed venous blood oxygen difference as did subjects without evidence of heart disease. The mean values at the end of exercise were: for $\dot{\mathrm{V}}_{\mathrm{O}_{2}}, 456$ ml. per minute per M. $^{2}$ (standard deviation $[\sigma]$ equals \pm 78.9 ); for $\dot{Q} a, 5.20 \mathrm{~L}$. per minute per M. ${ }^{2}(\sigma= \pm 1.49)$; and for $\left(\mathrm{Ca}_{\mathrm{O}_{2}}-\mathrm{C}_{\mathrm{v}_{O_{2}}}\right), 70.8$ ml. per L. $(\sigma= \pm 14.7)$. These levels represent changes from control of $282 \mathrm{ml}$. per minute per M. ${ }^{2}, 1.98 \mathrm{~L}$. per minute per M. ${ }^{2}$ and $26.4 \mathrm{ml}$. per L. Average values found in normal subjects (1) were $433 \mathrm{ml}$. per minute per $\mathrm{M}^{2}{ }^{2}(\sigma= \pm 81.2)$, 5.04 L. per minute per M. ${ }^{2}(\sigma= \pm 1.35)$ and $71.3 \mathrm{ml}$. per L. $(\sigma= \pm 15.4)$, respectively. Statistically the heart disease group was not different from normal in these respects, and no single value fell outside the normal range. The two groups were likewise identical at rest with respect to these measurements: $154(\sigma= \pm 10.1)$ and 151 $(\sigma= \pm 9.4) \mathrm{ml}$. per minute per $\mathrm{M}_{.}^{2}$ for $\dot{\mathrm{V}}_{\mathrm{O}_{2}}$, $3.22(\sigma= \pm 0.22)$ and $3.19(\sigma= \pm 0.29)$ L. per minute per M. ${ }^{2}$ for $\dot{Q} \mathrm{a}$, and $44.4(\sigma= \pm 6.2)$ and $44.1(\sigma= \pm 5.1) \mathrm{ml}$. per L. for $\left(\mathrm{Ca}_{2}-\mathrm{C}_{\mathrm{v}_{2}}\right)$. The average increase in blood lactate during exercise was about the same in patients with heart disease as in normal subjects : $1.54 \mathrm{mM}$ per L. $(\sigma= \pm 0.76)$ by comparison with $1.31(\sigma=$ $\pm 0.60) \mathrm{mM}$ per L. Changes in blood pyruvate also did not differ significantly from normal: $0.115 \mathrm{mM}$ per $\mathrm{L}$. $(\sigma= \pm 0.038)$ in the cardiac patients and $0.090 \mathrm{mM}$ per L. $(\sigma= \pm 0.032)$ in normals. Some individual total lactate increases were very high in the patients, as shown in the diagram of these values in Figure 1. As previously pointed out (2), however, none of these data give any reliable indication whether oxygen supply to the tissues by way of the circulation was adequate or not, or whether the heart disease which was present had impaired cardiac performance.

\section{Percentage response of oxygen consumption}

From the relationships between the changes in lactate and pyruvate, calculations of anaerobic metabolic rate (AMR) were made as shown by Equations 1 and 2. The 30 patients with heart disease exhibited AMR values between 4.5 and $41.8 \mathrm{ml}$. oxygen equivalents per minute, averaging $32.3(\sigma= \pm 8.42)$, which are not significantly different from normal. The values of $\mathrm{dXL} / \mathrm{dt}$ from which these are derived are shown diagrammatically in Figure 1. If these values are corrected for the varying severity of effort in different experiments by dividing by the total metabolic rates, the resulting indices average

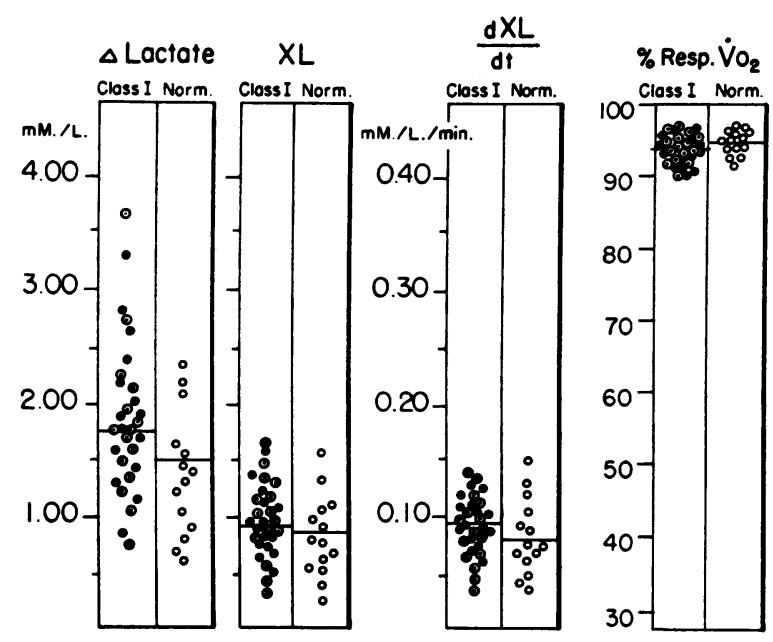

Fig. 1. Changes in Blood lactate (a Lactate), Excess lactate (XL), Rate of Accumulation of ExCess Lactate (DXL/DT), and Percentage Response of Oxygen Consumption in Subjects with Class I Heart Disease and in Normal Subjects

In the Class I column, shaded points indicate Group A; open points, Group B. 
$0.059(\sigma= \pm 0.0185)$, and are again not significantly different from normal. This figure may be otherwise expressed as the fractional adequacy of overall oxygen delivery or "percentage response of oxygen consumption" ( $\%$ resp. $\dot{\mathrm{V}}_{\mathrm{O}_{2}}$ ), which averages 94.1 per cent $(\sigma= \pm 1.85$ per cent), and is depicted in Figure 1. This value permits the conclusion that 94.1 per cent of the oxygen required by body tissues during mild exercise was supplied at the time of the need, and is indistinguishable from the response of normal subjects who have no heart disease. This observation seems consistent with the fact that these cardiac patients were active and well.

\section{Percentage response of cardiac output}

It nevertheless remained to be determined whether an inadequate cardiac response could have been associated with this adequate overall oxygen delivery. The response of cardiac output may also be expressed as a fraction of what it should be (the "percentage response of cardiac output"), calculated as shown in Equation 4. For this purpose the patients with Class I heart disease are initially considered under two headings : $a$ ) "mitral stenosis" and $b$ ) "aortic stenosis." Certain other forms of heart disease are subsequently added to one or the other of these groups.

The percentage response of cardiac output (\% resp. $\dot{Q} a$ ) was abnormal in all nine patients of Group A with atrio-ventricular valvular deformity. These figures are plotted in Figure 2 as scatter diagrams showing the $\%$ resp. $\dot{\mathrm{V}}_{\mathrm{O}_{2}}$ in the left hand column, \% resp. Q $\mathrm{Q}$ in the middle column and $\%$ resp. $(a-\bar{v})_{O_{2}}$ on the right. The three values obtained in a given subject in one exercise period are connected by lines to show their relationships. The range of values outlined by the block in the upper section of the chart encompasses the observations which have been made on normal subjects (1). The range blocked off in the lower section of the figure includes all values previously obtained in patients with definite congestive heart failure. All patients with recognizable mitral stenosis studied thus far have differed significantly, as shown in Figure 2, from both the normal and the heart failure groups in such a way that any single individual could have been placed properly with respect to diagnosis. These Class I patients invariably differed from those with mild heart failure in that they showed normal values for $\%$ resp. $\dot{\mathrm{V}}_{\mathrm{O}_{2}}$ and $\%$ resp. $(a-\bar{v})_{O_{2}}$ (above 90 per cent). However, each one differed from normal in having a reduced $\%$ resp. Q்a. . This was also true of two patients with cardiac dilatation without valvular disease ("arteriosclerotic" or senile myocardial disease), and the results of these two studies are included in Figure 2. Although the clinical diagnosis of mitral regurgitation or tricuspid regurgitation is less certain than that of mitral stenosis in some asymptomatic subjects, the same findings were obtained in four such patients, and these are also included in Figure 2. Of the nine patients with apical diastolic murmurs, six were found to have no abnormality of pulmonary arterial or wedge pressure at rest or during exercise. Three patients showed some elevation of pulmonary wedge pressure (above $8 \mathrm{~mm} . \mathrm{Hg}$ at rest; about $14 \mathrm{~mm}$. in exercise), and these three had the most marked depressions of \% resp. Q̇a. Resting pulmonary

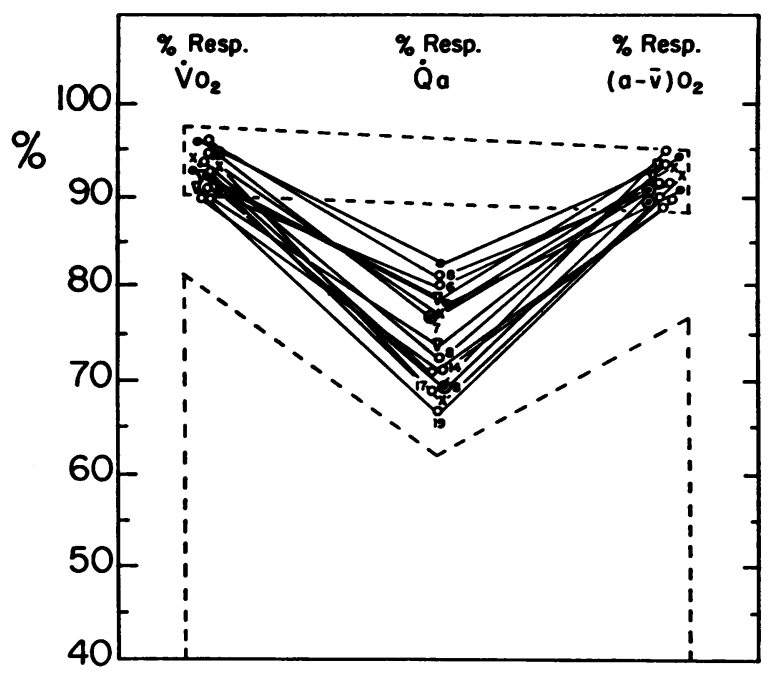

Fig. 2. Percentage Responses of Oxygen Consumption, Cardiac OUtPut and Arteriovenous OXYgen Difference in Patients of Group A

Group A: Class I mitral stenosis (open circles), mitral regurgitation (closed circles), senile heart disease (crosses) and tricuspid regurgitation (triangles). The three values obtained for each individual are connected by lines. The total range of normal values (1) is shown by the upper box, that for patients with clinical heart failure by the lower box. Numerals beside points in the second column indicate the pulmonary wedge pressures in the patients with mitral stenosis. The ages of the patients, in order of decreasing \% resp. $\dot{Q}$, are as follows: 18, 27, 19, 24, 31, $20,28,33,29,19,62,21,27,57$ and 30 years. 
wedge pressures in patients with mitral stenosis are indicated in Figure 2 beside the points representing \% resp. Q.a. Pressures were normal in the remainder of the 15 subjects.

Figure 3 shows the values of the three percentage responses in the 15 patients of Group B, with acceptable clinical evidence of semilunar valvular deformity or lesions having a similar hemodynamic effect on the heart. All asymptomatic patients with aortic stenosis who were studied presented findings which were indistinguishable from normal, as shown in Figure 3. This was also true of all patients studied who had systemic arterial hypertension and of two patients with pulmonic valvular disease. The findings were the same even when extreme cardiomegaly, electrocardiographic evidence of ventricular hypertrophy or angina pectoris were present. (In the cases with angina pectoris, of course, the term asymptomatic is applicable only in the sense that no exertional or nocturnal dyspnea and no fatigue or edema were noted.) Severe essential hypertension with diastolic pressures of $130 \mathrm{~mm}$. Hg, Grade III eye ground changes,

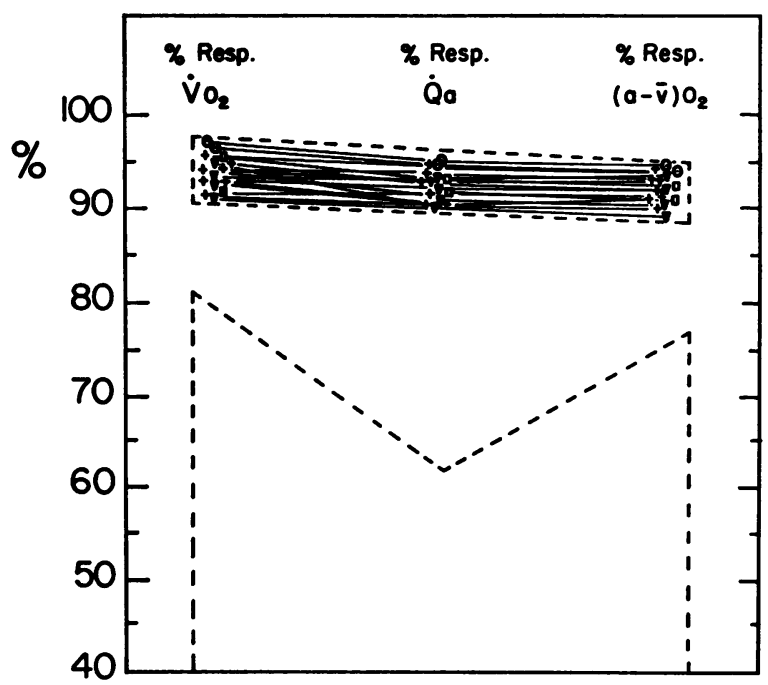

Fig. 3. Percentage Responses of Oxygen Consumption, Cardiac Output and Arteriovenous OXYgen Difference for Patients of Group B

Group B : Class I aortic valvular disease (ovals, stenosis alone; triangles, regurgitation or combination), pulmonic valvular stenosis (squares) and systemic arterial hypertension (crosses). Ages of the patients, in order of decreasing \% resp. $\dot{Q} \mathrm{a}$, are as follows: $46,48,52,39,61,54$, $41,59,63,45,47,56,58,49$ and 50 years. cardiomegaly and electrocardiographic changes likewise did not apparently alter the adequacy of cardiac output or of general oxygen delivery relative to peripheral tissue requirements.

\section{Effects of surgical treatment}

Figure 4 depicts the findings in a small number of patients with mitral stenosis at varying intervals after apparently satisfactory surgical mitral commissurotomy. These studies were carried out because of the possibility that such patients may have been converted by therapy into "Class I" patients (in the objective sense which the present data suggest for this term). Although many such patients may not be classified truly in Class I (asymptomatic), the observations of Figure 4 are shown together because the varied results seem as unrelated to subjective symptoms as are the data obtained in the truly asymptomatic subjects previously described. The only striking improvement immediately after operation is shown in Figure 4, Part B, data from a 35 year old woman who was apparently greatly improved subjectively, although not completely well. As can be seen from the points at the top of the chart, two patients (two and three years postoperative) finally presented the percentage response findings expected in Class I mitral deformity and another (one and one-half years postoperative) approached this state.

\section{Diagnostic evaluation of apical systolic murmurs}

Figure 5 shows the data obtained thus far in a general survey of asymptomatic patients with apical systolic murmurs. Some of these subjects have the definite abnormality of $\%$ resp. $\dot{Q} a$ characteristic of atrio-ventricular valvular disease, while others show normal values. It has not appeared possible by clinical examination and use of familiar criteria (3) to predict these results in every case. Similar surveys of the physiologic significance of other early signs occurring alone (i.e., opening snap, increased intensity of the first heart sound, and so forth) may prove to be of interest.

\section{DISCUSSION}

Occasional observations have been made in the past on patients with asymptomatic heart disease. The relationship of $\mathrm{O}_{2}$-debt development 


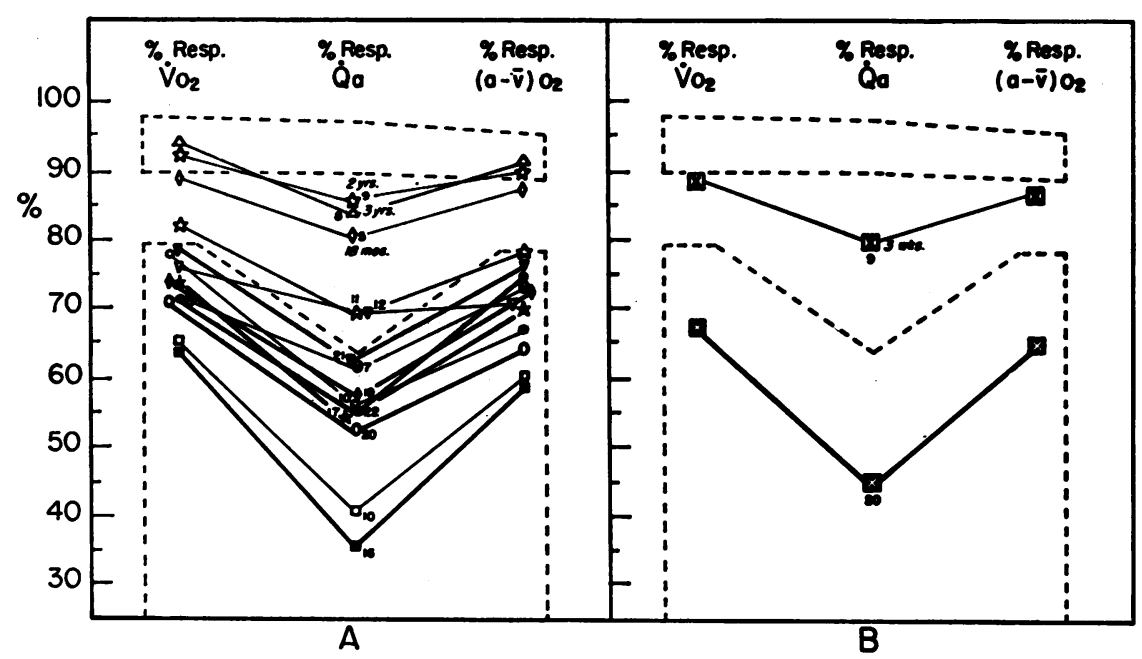

Fig. 4. Effect of Mitral Valvuloplasty (Open Symbols) on the Percentage Responses of Patients with Mitral Stenosis Who Had Clinical Congestive Failure Prior to Operation (Closed Symbols)

Section A shows lack of immediate effect in several patients (2 to 3 weeks postoperative except where otherwise indicated) with significant improvement in longer periods. Section B shows data from one patient ( $\%$, Class II-III) who exhibited marked improvement immediately.

to severity of exercise has been found to be the same as in patients with no organic heart disease (4), but this relationship was also normal in various published data on congestive heart failure (1) and therefore offers little help in understanding the course of the disease. Resting and exertional lactate concentrations in arm venous blood have been noted to be normal in several such patients (5). Richards (6) stated that no circulatory abnormalities were demonstrable on cardiac catheterization. However, reduced renal blood flow has been found in asymptomatic patients with heart disease (7).

Although the present observations indicate that high levels of total lactate may occur in the arterial blood of a small proportion of patients with asymptomatic heart disease, most of these patients are indistinguishable from normal persons in this respect. Similar unusual degrees of lactate accumulation may of ten be seen in normal subjects who believe they have heart disease and feel anxiety about physical exertion; this finding seems more probably related to the psychogenic ventilatory response to exercise (8). In any event, the rate of accumulation of "excess lactate" or the rate of tissue anaerobic metabolism in mild exercise is only about 6 per cent of the total energy requirement and therefore does not differ from that of normal people as far as can be determined, even in those patients in whom total lactate response is exaggerated.

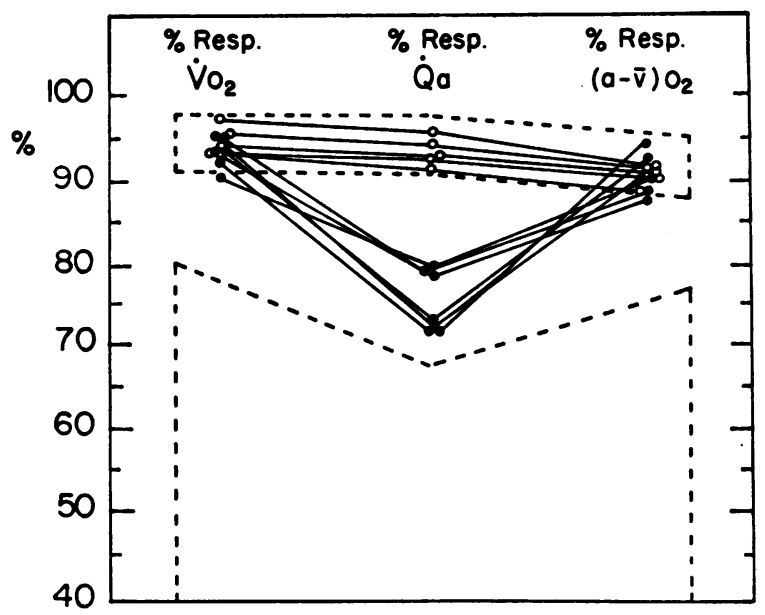

Fig. 5. Percentage Responses in a Group of Asymptomatic Subjects with No Other Clinical Abnormality Than an Apical Systolic Murmur

The data tend to fall into two groups, one of which is normal (open circles, falling inside the upper block denoting normal range), the other definitely abnormal by the criteria of Figure 2. 
On the basis of the small variance of some of the data shown, certain empirical relationships may be said to obtain commonly among $\dot{\mathrm{V}}_{\mathrm{O}_{2}}$, $\dot{\mathrm{Q}} \mathrm{a}$, and $\left(\mathrm{Ca}_{\mathrm{O}_{2}}-\mathrm{C}_{\mathrm{v}_{2}}\right)$ in patients with Class I heart disease. Since the $\%$ resp. $\dot{\mathrm{V}}_{\mathrm{O}_{i}}$ is normal, it may be assumed that AMR can be estimated from $\Delta \dot{\mathrm{V}}_{\mathrm{O}_{2}}$ with moderate accuracy, i.e., AMR averages about 5 per cent of $\Delta \dot{\mathrm{V}}_{\mathrm{O}_{2}}$. The following relationship, derived from the equation for $\%$ resp. $\dot{Q}$ a, would therefore have a certain statistical validity as a rule of thumb:

$$
\% \text { resp. } \dot{\mathrm{Q}} \mathrm{a}=\frac{\Delta \dot{\mathrm{Q}} \mathrm{a} \times 100}{\Delta \dot{\mathrm{Q}} \mathrm{a}+\frac{0.05 \Delta \dot{\mathrm{V}}_{\mathrm{O}_{2}}}{\left(\mathrm{Ca}_{\mathrm{O}_{2}}-\mathrm{C}_{\overline{\mathrm{O}}_{2}}\right)_{\text {ex }}}}
$$

This empirical equation is derived from the data obtained from the present normal subjects and patients with asymptomatic aortic or pulmonic valvular disease or essential hypertension. In normal subjects \% resp. Q $\mathrm{Q}$ is also an empirical constant, and the equation therefore simplifies to a more basic principle :

$$
\Delta \dot{\mathrm{Q} a}=\mathrm{K} \frac{\Delta \dot{\mathrm{V}}_{\mathrm{O}_{2}}}{\left(\mathrm{CaO}_{2}-\mathrm{C}_{\mathrm{O}_{2}}\right)_{\mathrm{ex}} .} .
$$

The mean value of the constant $\mathrm{K}$ is $0.625 .^{3}$ If this equation is plotted as cardiac output against arteriovenous oxygen difference, the result is a family of falling hyperbolic curves, one for each value of $\Delta \dot{\mathrm{V}}_{\mathrm{O}_{2}}$. Patients with atrioventricular valvular deformities, however, do not fit this prediction, but give points which lie below the appropriate curve in each case. The equation, therefore, suggests that a principle governed the relationships among cardiac output, oxygen consumption and arteriovenous oxygen difference as they increased during exercise in the patients of this series, a principle which is somewhat different from that usually thought of clinically. Rather than a "normal value" for cardiac output for any given degree of exertion, or even a normal value for the relationship of cardiac output to arteriovenous oxygen difference at any given

3 While this equation may at first seem to resemble that of the Fick principle (which, of course, expresses all possible values without selection), it is well to point out that the Fick principle dictates only the following relationship among the terms of Equation 6:

$$
\Delta \dot{Q}_{a}=\frac{\dot{\mathrm{V}}_{\mathrm{O}_{2} \text { ex. }}\left(\mathrm{Ca}_{\mathrm{O}_{2}}-\mathrm{C}_{\mathrm{O}_{2}}\right)-\dot{\mathrm{V}}_{\mathrm{O}_{2}}\left(\mathrm{CaO}_{2}-\mathrm{C}_{\mathrm{O}_{2}}\right)_{\text {ex. }}}{\left(\mathrm{Ca}_{\mathrm{O}_{2}}-\mathrm{C}_{\mathrm{V}_{2}}\right)\left(\mathrm{Ca}_{\mathrm{O}_{2}}-\mathrm{C}_{\mathrm{O}_{2}}\right)_{\text {ex. }}} .
$$

oxygen consumption, there would appear to be a whole series of normal values lying along one of the curves of the graph, the locations of the curves being determined by the value of $K$. If a patient's cardiac output is small and his arteriovenous oxygen difference is relatively large, one is tempted to suppose that this represents an impairment to oxygen supply and therefore an abnormality. In fact, as the arteriovenous oxygen difference widens, less blood flow will be required to supply the oxygen needs of the tissues, as illustrated by the negative slopes of the curves. Of course a blood flow which is really excessively low for the existing arteriovenous oxygen difference will fall below all parts of the appropriate normal curve, but the finding per se of a larger arteriovenous difference and smaller cardiac output in one group of subjects than another does not mean that cardiac output is "insufficient."

Application of Equation 5 to 137 published studies of normal cardiac output by various methods in exercise gives estimated percentage responses of cardiac output of 89 per cent or more (9-17). Data from one patient with Class I mitral disease have been given previously (18) and show a significantly reduced \% resp. Q́a, while two patients with Class I aortic valvular disease (19) showed normal values.

The finding of definite abnormalities of cardiac output response in the early stages of the development of chronic mitral stenosis suggests the possibility that a more prolonged course of events than is usually supposed may form the physiologic history of congestive heart failure of this etiology. Judging from the abnormalities in these Class I patients (i.e., those with early disease), the years during which the obvious dyspnea of mitral stenosis appears and grows worse may be only the last third of the course of continuous circulatory change which, like the endocarditis itself, began long before the first dyspnea appeared.

Several questions are raised by this interpretation. The first is in regard to the possible mechanism of a limitation of cardiac output response apparently produced by such early deformity of the valve. Lewis (20) held that blood flow could not be importantly affected until the valve orifice had been markedly reduced, and 
this has also been the interpretation placed on results of certain experiments on hydraulic systems and on animals (21-23). Explanations of the present results presumably must lie in the slight interference to blood flow through the valve produced by turbulence in the stream, but Class I aortic valvular deformity does not produce the same result. The pressure available for effecting flow through atrioventricular valves is low at this stage. Compensation by the pulmonary venous bed for a slight resistance to flow cannot occur in the same way as if blood were driven through the valve directly by ventricular contraction. An adequate increase in pressure at this time would presumably restore blood flow to normal. If it can be supposed that the pressure gradient required to overcome the early valvular deformity is eventually provided, by the time the pressure has risen the valvular deformity must also have progressed since the percentage response of cardiac output was not found to be improved in the subjects with elevated pulmonary wedge pressures, but was either the same or lower.

A second question is in regard to the lowered oxygen consumption response, which was found only in patients in whom the adequacy of cardiac output was below about 70 to 75 per cent [the lowest seen in the present data, all lower values having been found in patients with heart failure and reduced $\%$ resp. $\left.\dot{\mathrm{V}}_{\mathrm{O}_{2}}(1)\right]$. Whether the ultimate appearance of insufficiency of overall oxygen supply may be related causally to the appearance of clinical heart failure, which seems to occur only in its presence, is not evident from the available data, but is suggested by the fact that no cases have yet been observed which fall into an intermediate zone, i.e., patients who show a reduced $\%$ resp. $\dot{\mathrm{V}}_{\mathrm{O}_{2}}$ with no symptoms or signs of cardiac failure, or who show clinical heart failure without reduction of $\%$ resp. $\dot{\mathrm{V}}_{\mathrm{O}_{2}}$. Continued study may reveal that there are such cases, however.

No such physiologic history preceding the heart failure of aortic valvular deformity or systemic hypertension appears to be implied by the present observations on the early stages of these lesions. It is possible that the adequacy of cardiac output remains unimpaired until clinical heart failure has actually occurred. After this event the physiologic findings have been shown to be the same, whatever the etiology of the heart failure (1). An explanation for this difference may perhaps be found in the fact that blood is propelled through the semilunar valves by the immediately proximal muscular ventricle, which is known to increase its force of contraction in response to increased resistance to flow $(24,25)$. If the present patients are representative of the group as a whole, more or less complete compensation for the valvular deformity by the ventricle may continue until the ventricular muscle itself fails. Corollary events in the life of such a patient might be expected, therefore, to be somewhat different from those produced by atrioventricular valvular disease with its continuous course, physiologically speaking, almost from the first.

In patients with aortic valvular disease there thus appears to be some physiologic basis for understanding that 40 years of active, normal life elapse after acute rheumatic fever, only to be ended by a period of congestive heart failure which runs its course to a fatal termination in a few months (26). This pattern is quite different from one of 10 years of health followed by 5 or more years of symptomatic cardiac insufficiency, the course described for atrioventricular valvulitis by the statistics of DeGraff and Lingg (27), even though their patients were selected for severity of inflammatory disease (by virtue of giving a definite history of acute rheumatic fever) and the mean time of death was not corrected for causes other than cardiac decompensation. The present findings might also be taken to suggest that semilunar valvular deformity would have no influence on the physiologic history of atrioventricular valvular disease if the two occurred together; clinical observations indicate a similar principle may apply to the symptomatic history (28). Students of the clinical course of aortic valvular disease have repeatedly remarked on its prolonged and benign behavior prior to decompensation, and the rapid demise afterward (29-31). These observations are a reflection on the occurrence of congestive heart failure and not on the unpredictable possibilities of sudden death or bacterial endocarditis. The generalizations, of course, are subject to individual variations. Experience has shown that untreated systemic 
arterial hypertension likewise produces no limitation of activity over a major portion of the patient's lifetime, although many nervous symptoms may be present; heart failure may occur rapidly, however, and in severe hypertension progress precipitously.

In view of the supposed implications of the present results with regard to the adequacy of the responses of the heart to meet body needs, it is interesting that the age of the patients also seemed to have no effect on the findings. The difficulty of subdividing the narrowly-grouped figures in the normal range, however, has already been mentioned. There may be some broad tendency toward age dependence in all the groups, but the statistical correlation is not significant. A 3 to 4 per cent variation of the percentage responses in the normal group and among the patients with aortic and pulmonic valvular disease and essential hypertension can only be regarded as unexpectedly constant, even assuming a single population of data.

The course of change of the findings in the present small group of patients during two to three years following mitral valvuloplasty might be interpreted as being the reverse of the physiologic pathogenesis of mitral stenosis. The almost complete lack of change in percentage response of cardiac output two to three weeks after surgery in most patients is difficult to explain, since pulmonary arterial and "wedge" pressures were reduced. Mitral regurgitation may replace mitral stenosis in some of these patients, and the characteristic low pulmonary vascular pressures associated with mitral regurgitation may be present; adequacy of cardiac output responses, on the other hand, may not always be improved by this change.

The findings in two cases of unexplained cardiac dilatation may possibly serve to indicate that the course of development of heart failure from senile or "arteriosclerotic" myocardial disease is more nearly like that of Group A (atrioventricular valvular disease) than Group B. It may, however, be shorter in duration than that of mitral stenosis, judging from the subsequent history of these patients. Both patients subsequently developed frank congestive heart failure, one within a year, the other after 26 months, but were easily controlled with digitalis. All but four of the remaining subjects of Group A have remained well after one to four years. Four patients with mitral stenosis (including the three with elevated pulmonary vascular pressures) began to suffer slight dyspnea on exertion two to four years after the study, and the dyspnea grew worse over a period of six months or more. Two patients of Group B (aortic stenosis and regurgitation) subsequently died of rapidly progressive congestive heart failure after remaining well for 16 and 34 months, respectively, following the study. It is interesting to speculate that the Group A findings (depression of \% resp. $\dot{Q}$ a) will in the future probably be found in some hypertensive patients when a larger number have been studied, since the development of senile or "arteriosclerotic" heart disease is assumed to account for the ultimate occurrence of heart failure in at least some patients with essential hypertension. The same speculation may also be entertained about "normal" subjects as the number of observations increases, since unrecognized cardiac dilatation or "aphonic" mitral stenosis might occur among presumed normal subjects.

Some of the physiologic characteristics of the calculated "percentage response of cardiac output" have been given previously, and these may be extended somewhat on the basis of the present data. This value may have any magnitude equal to or less than \% resp. $\dot{\mathrm{V}}_{\mathrm{O}_{2}}$. It now appears possible to state empirically that if \% resp. $\dot{\mathrm{Q} a}$ does have a value less than $\%$ resp. $\dot{\mathrm{V}}_{\mathrm{O}_{2}}$, heart disease will be found to be present, even if $\%$ resp. $\dot{\mathrm{V}}_{\mathrm{O}_{2}}$ is normal. Of course if $\%$ resp. $\dot{\mathrm{V}}_{\mathrm{O}_{2}}$ were 95 per cent, one would conclude that the energy requirement of the tissues only slightly exceeded the total oxygen transport, although the requirements might at the same time exceed the blood flow response considerably. Aside from this tentative empirical conclusion on the association of heart disease and reduced \% resp. $\dot{Q} \mathrm{a}$, based on the present observations, the theo retical basis of this principle may be deduced from the Fick equation $\left(\mathrm{Ca}_{2}-\mathrm{C} \overline{\mathrm{v}}_{\mathrm{O}_{2}}=\dot{\mathrm{V}}_{\mathrm{O}_{2}} / \mathrm{Q} \mathrm{Q} \mathrm{a}\right)$ which indicates the rise in $\left(\mathrm{Ca}_{2}-\mathrm{C} \overline{\mathrm{v}}_{\mathrm{O}_{2}}\right)$ which will occur if increase in oxygen utilization by tissues occurs at a greater rate (percentage-wise) than the simultaneous increase in blood flow, even without considering the possibility of an AMR in addition. This phenomenon, of course, 
is generally recognized. From the equations for percentage response of cardiac output and percentage response of oxygen consumption, it is apparent that for any value of $\%$ resp. $\dot{\mathrm{V}}_{\mathrm{O}_{2}}$ (i.e., for any given value of the relationship between anaerobic metabolic rate and change in oxygen consumption) \% resp. Q $\mathrm{Q}$ can be less than this in only one circumstance, i.e., if the cardiac output has failed to increase in some "proper" proportion to oxygen utilization. This conclusion, however, must be regarded as purely qualitative. How much less the \% resp. Q́a will be is another question. From the equation, one may say that this will not be determined by the size of the arteriovenous oxygen difference, but by the relationship between arteriovenous oxygen difference and the magnitude of the anaerobic metabolic rate. The selective depression of $\%$ resp. Q́a below \% resp. $\dot{V}_{O_{i ̈}}$, therefore, apparently always represents the effect of reduced relative cardiac response whatever may be the values of other parameters, including \% resp. $\dot{\mathrm{V}}_{\mathrm{O}_{2}}$ or $\dot{\mathrm{Q}} \mathrm{a}$ itself, or the presumed clinical condition of the patient.

When observations of the sort presented here are made for diagnostic purposes in patients of unknown cardiac status, great care is used in establishing an initial "near-basal" state. However, no attempt is made to regulate the amount of exercise performed or its duration beyond about three to four minutes, which appear to be required for stability of $\dot{\mathrm{V}}_{\mathrm{O}_{2}}$. Moreover, examination of the figures for total body water reveal that this determination may be omitted in subjects judged to be of "normal" weight and build without introducing sufficient error in the calculation of percentage responses to affect the general clinical conclusions $\left[\mathrm{W}_{\mathrm{b}}\right.$ being estimated from body weight (31)]. Asymptomatic subjects with apical systolic murmurs have been briefly surveyed, as shown in Figure 5. While a final judgment of the medical significance of some of the abnormal findings will require a long term follow-up, it is noteworthy that a portion of this preliminary group of patients show percentage responses which are abnormal in the same way that patients with definite mitral stenosis are abnormal. Among the six patients who thus gave physiologic evidence of atrioventricular valve abnormalities, two were evaluated clini- cally as having normal hearts. Among the five patients with percentage response values indistinguishable from normal, two had been diagnosed clinically as having mitral valvular disease, at least tentatively. The data cannot indicate whether semilunar valvular abnormalities might have been present in any of the patients, but congenital septal defects probably may be excluded in these subjects because cardiac catheterization failed to give any evidence of them, and because certain characteristic effects on percentage responses produced by such lesions were not present; these effects cannot be adequately described here and will be presented elsewhere.

None of the data reported here or previously (1) include any observations made on subjects whose clinical state was impossible to evaluate, or at least categorize, by independent means. Needless to say, this is a most important group of patients. Thus far, however, the findings obtained by the present methods in such patients have fallen distinctly into one or another of the categories described; they have often been perfectly normal, but on occasions have shown the percentage responses characteristic of Class I heart disease or even of congestive heart failure (1).

\section{SUMMARY AND CONCLUSIONS}

1. Patients with clinical evidence of heart disease but no symptoms of congestive heart failure have an adequate response of the oxygen transport system during mild exercise so that body tissues are forced to rely on anaerobic metabolism to only a very small extent.

2. Patients with atrioventricular valvular deformities may have an inadequate response of cardiac output before any other measurable physiologic change occurs, and this may appear and grow worse for at least four years before clinical cardiac insufficiency appears.

3. By contrast, patients who have had semilunar valvular deformities or essential hypertension for years, even with evidence of myocardial deterioration, usually have an adequate cardiac output response unless full blown congestive heart failure is present.

4. Changes in cardiac output and arteriovenous oxygen difference are not reliable indications in themselves of normal or adequate cardiac responses. 


\section{ACKNOWLEDGMENT}

The author is indebted to Dr. Robert W. Wilkins for advice and criticism throughout, to Dr. Walter E. Judson for assistance in obtaining the cardiac catheterization data in the surgical cases, and to Miss Adele Rymut and Mrs. Lois Sack for technical assistance.

\section{REFERENCES}

1. Huckabee, W. E., and Judson, W. E. The role of anaerobic metabolism in the performance of mild muscular work. I. Relationship to oxygen consumption and cardiac output, and the effect of congestive heart failure. J. clin. Invest. 1958, 37, 1577.

2. Huckabee, W. E. Relationships of pyruvate and lactate during anaerobic metabolism. III. Effect of breathing low-oxygen gases. J. clin. Invest. 1958, 37, 264.

3. Levine, S. A., and Harvey, W. P. Clinical Auscultation of the Heart. Philadelphia, W. B. Saunders Co., 1949.

4. Herbst, R. Der Gasstoffwechsel als Mass der körperlichen Leistungsfähigkeit. III. Untersuchungen an Herzkranken. Dtsch. Arch. klin. Med. 1928, 162, 257.

5. Hallock, P. Lactic acid production during rest and after exercise in subjects with various types of heart disease with special reference to congenital heart disease. J. clin. Invest. 1939, 18, 385.

6. Richards, D. W., Jr. Dynamics of congestive heart failure. Amer. J. Med. 1949, 6, 772.

7. Heller, B. I., and Jacobson, W. E. Renal hemodynamics in heart disease. Amer. Heart J. 1950, 39, 188.

8. Huckabee, W. E. Relationships of pyruvate and lactate during anaerobic metabolism. I. Effects of infusion of pyruvate or glucose and of hyperventilation. J. clin. Invest. 1958, 37, 244.

9. Bock, A. V., Vancaulaert, C., Dill, D. B., Fölling, A., and Hurxthal, L. M. Studies in muscular activity. III. Dynamical changes occurring in man at work. J. Physiol. 1928, 66, 136.

10. Christensen, E. H. Minutenvolumen und Schlagvolumen des Herzens während schwere körperlicher Arbeit. Arbeitsphysiologie 1931, 4, 470.

11. Asmussen, E., and Nielsen, M. The cardiac output in rest and work determined simultaneously by the acetylene and the dye injection methods. Acta physiol. scand. 1952, 27, 217.

12. Sleator, W., Jr., Elam, J. O., Elam, W. N., Jr., and White, H. L. Oximetric determinations of cardiac output responses to light exercise. J. appl. Physiol. $1951,3,649$.

13. Hickam, J. B., and Cargill, W. H. Effect of exercise on cardiac output and pulmonary arterial pressure in normal persons and in patients with cardiovascular disease and pulmonary emphysema. $\mathrm{J}$. clin. Invest. 1948, 27, 10.

14. Riley, R. L., Himmelstein, A., Motley, H. L., Weiner, H. M., and Cournand, A. Studies of the pulmonary circulation at rest and during exercise in normal individuals and in patients with chronic pulmonary disease. Amer. J. Physiol. 1948, 152, 372.

15. Hamilton, W. F., Riley, R. L., Attyah, A. M., Cournand, A., Fowell, D. M., Himmelstein, A., Noble, R. P., Remington, J. W., Richards, D. W., Jr., Wheeler, N. C., and Witham, A. C. Comparison of the Fick and dye injection methods of measuring the cardiac output in man. Amer. J. Physiol. 1948, 153, 309.

16. Dexter, L., Whittenberger, J. L., Haynes, F. W., Goodale, W. T., Gorlin, R., and Sawyer, C. G. Effect of exercise on circulatory dynamics of normal individuals. J. appl. Physiol. 1951, 3, 439.

17. Donald, K. W., Bishop, J. M., Cumming, G., and Wade, O. L. The effect of exercise on the cardiac output and circulatory dynamics of normal subjects. Clin. Sci. 1955, 14, 37.

18. Gorlin, R., Haynes, F. W., Goodale, W. T., Sawyer, C. G., Dow, J. W., and Dexter, L. Studies of the circulatory dynamics in mitral stenosis. II. Altered dynamics at rest. Amer. Heart J. 1951, 41, 30.

19. Goldberg, H., Bakst, A. A., and Bailey, C. P. The dynamics of aortic valvular disease. Amer. Heart J. 1954, 47, 527.

20. Lewis, T. Diseases of the Heart. London, MacMillan and Co., 1946.

21. Allan, G. A. A schema of the circulation with experiments to determine the additional load on the apparatus produced by conditions representing valvular lesions. Heart 1926, 12, 181.

22. Shaw, M. M., Adams, W. E., Rasmussen, R. A., Hrdina, L. S., and Aronson, H. G. Experimental production of insufficiency and stenosis of the heart valves in dogs. J. thorac. Surg. 1942, 12, 322.

23. Haddy, F. J., Ferrin, A. L., Hannon, D. W., Alden, J. F., Adams, W. L., and Baronofsky, I. D. Cardiac function in experimental mitral stenosis. Circulat. Res. 1953, 1, 219.

24. Patterson, S. W., Piper, H., and Starling, E. H. The regulation of the heart beat. J. Physiol. 1914, 48, 465.

25. Barger, A. C., Ross, R. S., and Price, H. L. Reduced sodium excretion in dogs with mild valvular lesions of the heart, and in dogs with congestive failure. Amer. J. Physiol. 1955, 180, 249.

26. Contratto, A. W., and Levine, S. A. Aortic stenosis with special reference to angina pectoris and syncope. Ann. intern. Med. 1937, 10, 1636.

27. De Graff, A. C., and Lingg, C. The course of rheumatic heart disease in adults. I. Amer. Heart J. 1934, 10, 459.

28. De Graff, A. C., and Lingg, C. The course of rheumatic heart disease in adults. II. Amer. Heart J. 1934, 10, 478.

29. Clarke, J. M. Some features of aortic regurgitation in young subjects. Brit. med. J. 1911, 1, 1364.

30. Coombs, C. F. Rheumatic Heart Disease. New York, William Wood and Co., 1924.

31. Huckabee, W. E. Use of 4-aminoantipyrine for determining volume of body water available for solute dilution. J. appl. Physiol. 1956, 9, 157. 